\title{
Home Automation System Support for Persons with Different Types of Disabilities using IoT
}

\author{
Ayad Ghany Ismaeel ${ }^{1}$ \\ \{ ayad.ghany@uoalkitab.edu.iq \} \\ Department of Computer Technical Engineering, Technical Eng. College, Al-Kitab University, Iraq ${ }^{1}$
}

\begin{abstract}
In general the Home Automation Systems HASs are designed for nondisabled persons, some of which suggested for specific disabled persons, i.e. only for physical, visual, hearing or cognitive persons. This article introduces an IoT home integrated device in two sections: the hardware and software have been developed to simplify the usage of IoT via voice recognition apps for disabled people, using the feedback machine based on Microphone MIC / Mobile. The Raspberry Pi development board is the processing tool utilized, and the project also intends to provide consumers with a voice recognition system for operating machines. An online Speech-To-Text interface called (wit) which is used to understand the expression. The home automation program listens to the user's voice and when a certain word is mentioned, turning the systems on or off contributes to identical behavior. Implementation of this new framework (HAS) has been done in an economical way, easy to install and configure, it is used for different types of people with disabilities via input voice data from a stable and efficient cloud web platform for the user to monitor household appliances via IoT
\end{abstract}

Keywords: Home Automation, Persons with Disabilities, Raspberry PI, Speech Recognition, IoT, Cloud, Wi-Fi, Mobile App.

\section{Introduction}

Technological advances and access to Internet in the past decade have allowed the concept of connecting everyday things to Internet to become a useful fact. The IoT requires actionsensing mechanisms, which may come from various sources and shapes, such as barcode scanning, motion and temperature sensing, or facial expression recognition. On the other hand, it requires a platform for humans or other things to handle or respond to data that is entered into the system. As such, the IoT creates an automated communication system that can be between human-inanimate, inanimate-inanimate or inanimate-human.

Using this concept as a tool to improve human life is currently a new field of innovation with endless opportunities. With access to the Internet in many countries around the world, we believe it is time to start taking action to use IoT as a way to support people with disabilities [1].

The important aims of IoT are:

- Enhanced activities.

- Save some precious energy and resources.

- Boost quality of living. 
Table 1. shows the common examples of useful functionalities enabled by IoT [2]

\begin{tabular}{cc}
\hline Type of Disability & Examples of Useful Functionalities Enabled by IoT \\
\hline Physical and Dexterity & Remote Assistance, Home automation, Voice commands \\
Visual & Help to find the way, Voice commands, \\
Help for reading and interacting \\
Hearing & Optical signals on glasses \\
Cognitive & Optical signals on the smartphone \\
\hline
\end{tabular}

\section{RELATED WORK}

Ayad G. Ismaeel and Mohammed Q. Kamal (2018) proposed IoT home automated system (for disabled and non-disabled persons) in hardware Through creating a system called (Worldwide Auto-mobi), and utilizing preferred tools such as TV, SAT, DVD, the program has streamlined. In contrast with another system which can be monitored by an IR sensor, directly and indirectly, through a prototype smartphone app, the number of input devices employed in the home can be reduced by using a simple phone software that dominates devices using the Internet-based Arduino UNO and ESP8266 Wi-Fi node. This device will accommodate iPhone and android smartphones or iPad / Tablet that is attached to a central server and phone app. Implementing the present model was accomplished at a low-cost (exceeds 30 USD) for warehouse/home equipment with respect to latency in the period (0.4 to 1$)$ second, which will be close to the real-time (in a few Secs) that could be attained anywhere and at any time depending on the server. The major disadvantages are that the library scale for transmitting IR commands are restricted, and the device is updated to several actuating alerts using web (http://arest.io/cloud,18-3-2020) [3].

Shih-C. Chen, Chung-M. Wu, \& et al (2017) presented and analyzed the current application of the Morse Text Input Controller (McTin) household appliance functionality developed by the testing team for people with serious disabilities and evaluated the living nature of the impairment problem depending on the working frequency of various home appliances. The key downside of this design is that the system was restricted, which could be attributed to the insecurity of wireless connectivity between the Computer and Arduino. Besides, the model developed by the study team is for particular individuals with extreme disabilities only. [4].

Mohd H. Abd Wahab's (2016) indicated that a home automation program focused on IoT was intended to support people with serious difficulties and the elderly persons. This offered assistance as well as monitoring of electrical equipment and controls ambient temperature via smartphone technologies. The architecture utilizes the constructed-in dashboard, and the household appliances are mechanically linked through circuits to the supply terminals of this device. The central control panel utilizes wireless networking systems to include remote connectivity from the laptop or mobile. Cytron BlueBee is being utilized to create a wireless link between the Android device and the Arduino unit. The smartphone device has been configured to include a simple-to-use graphical user interface (GUI) for the motion sensor of 
household appliances. The key downside of this GUI-provided device can be fitted with sound modulation for voice recognition and home control system [5].

The motivation of this article is to review the systems that support disabled persons based on IoT and determine their main drawbacks and how they can overcome their drawbacks.

\section{PROPOSED AUTOMATED SYSTEM}

The conceptual concept incorporates a steady-cost home control device utilizing IoT technologies and voice recognition. The machine platform employed is the Raspberry Pi Design Committee. The proposed concept further seeks to provide a voice recognition system allowing consumers to monitor apps. Voice recognition is supported by the use of an internet-based Speech-To-Text tool named wit. This control system of the house listens to the user's voice, and when a particular sentence is defined, similar action will be taken to turn household devices ON or OFF. Through voice recognition the machines can be operated more effectively by disabled persons, Figure 1 shows the scenario of proposed HAS. The key priorities of the current home control framework can be summarized as follows:

- Exposure to an easy to mount and customize, low-cost home automation device.

- Offering a stable and efficient web platform for users to monitor their home appliances via IoT system.

- Building a voice communication system to monitor electronic/electric equipment for people with disabilities.

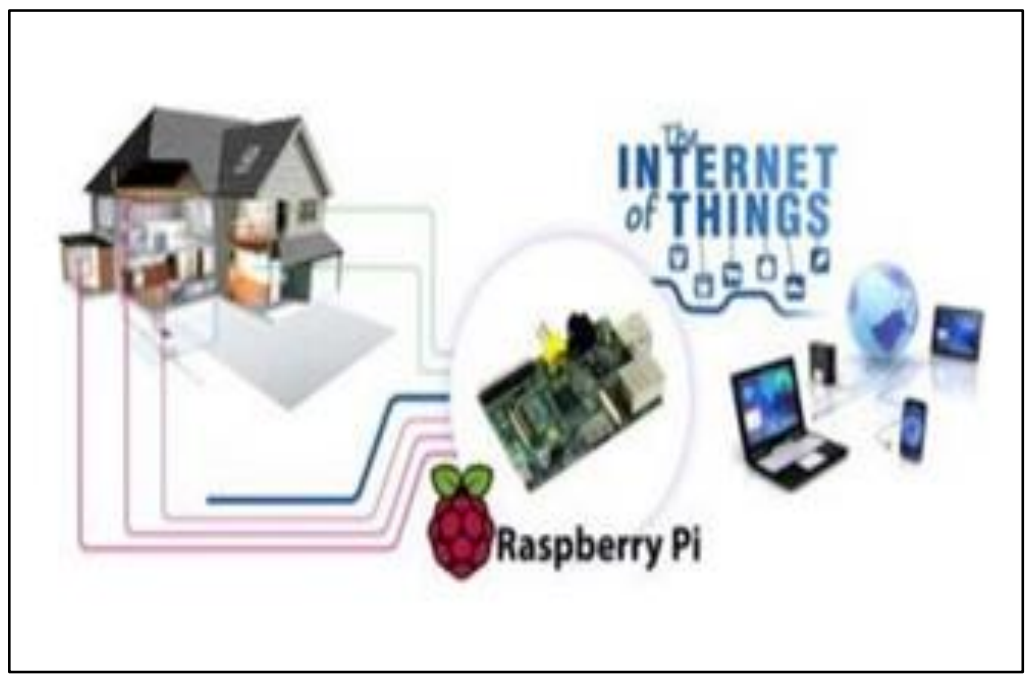

Fig.1. Shows the suggested HAS using MIC.

The given house automation system for persons with disabilities contains two main categories as follows:

\subsection{Speech Recognition to turn the devices $\mathrm{ON}$ or $\mathrm{OFF}$}


These categories care in to take the user events by speech to run the corresponding action for a specific device via the proposed system as shown in the following algorithm:

\section{Program Project;}

Step 1: Input user speech using via MIC or Mobile.

Step 2: Output Content of files (relay1.txt- relay4.txt) ON or

OFF based on the request of the user by speech, and that acts each GPIO pin turn up=ON and down=OFF.

Step 3: As the consumer expresses speech via the Microphone / Phone or tablet. The message is captured by python based WAV guidance and sent to a device with a special API code given using wit profile.

Step 4: Utilizes a Python program (for voice recognition), which utilizes a voice-recognition system to store and process expression.

Step 5: The Voice-To-Text framework is utilized by the API to translate voice to text.

Step 6: The document is then submitted back to the Python file, in python script it is checked for turning up (1) or down (0) machines with pre-set instructions.

Step 7: If: The sentence ON matches the obtained message and the matching string $(\mathrm{ON})$ is given in the matching posting script.

Else: The associated string (OFF) is inserted into the accompanying posting script.

Step 8: A Python code tracks the file information for all relays (relay1.txt-relay4.txt) depending on each relay output (i.e. more than one client at a time) as follows:

*relay 1.txt If: content file $=" \mathrm{ON}$ pin up

Else: content file $=$ "OFF" Python turn GPIO pin down

*relay2.txt If: content file ="ON" pin up

Else: content file $=$ "OFF" Python turn GPIO pin down

*relay3.txt If: content file ="ON" pin up

Else: content file $=" \mathrm{OFF}$ Python turn GPIO pin down

*relay4.txt If: content file $=" \mathrm{ON} " \quad$ Python turn GPIO pin up

Else: content file ="OFF" Python turn GPIO pin down

\subsection{Web Interface}

Raspberry pi executes system management webpages via the Apache remote server. The following Website are: 
A. Index.html: The index page works as a main web page. When the user signs in with the username and password, the user will be routed to the terminal page after defining the access parameter and the user will be routed to the login page.

B. Checklogin.php: The login page verifies the credentials with pre-defined credentials.

C. Controller.php: On the control page, the user can turn the device on or off with the buttons. There is a specific file for each relay that contains the string "ON" or "OFF".

D. Button.php: Once the button is pushed, a button page is named that tests ID of the button and sends the correct sequence to the relevant mailing address. A Python file is named iot.py. It tracks the contents of files for all relays (relay1.txt-relay4.txt). Depending on the contents of the script, i.e. "ON" or "OFF," the serpent text switches the GPIO pin high or low for each of the linked series. The relay is then activated either ON or OFF depending on user feedback and whatever the computer you are connected to for online tracking.

E. Logout.php: The logout page which turns off the system. Figure 2 shows the construction of the proposed System.

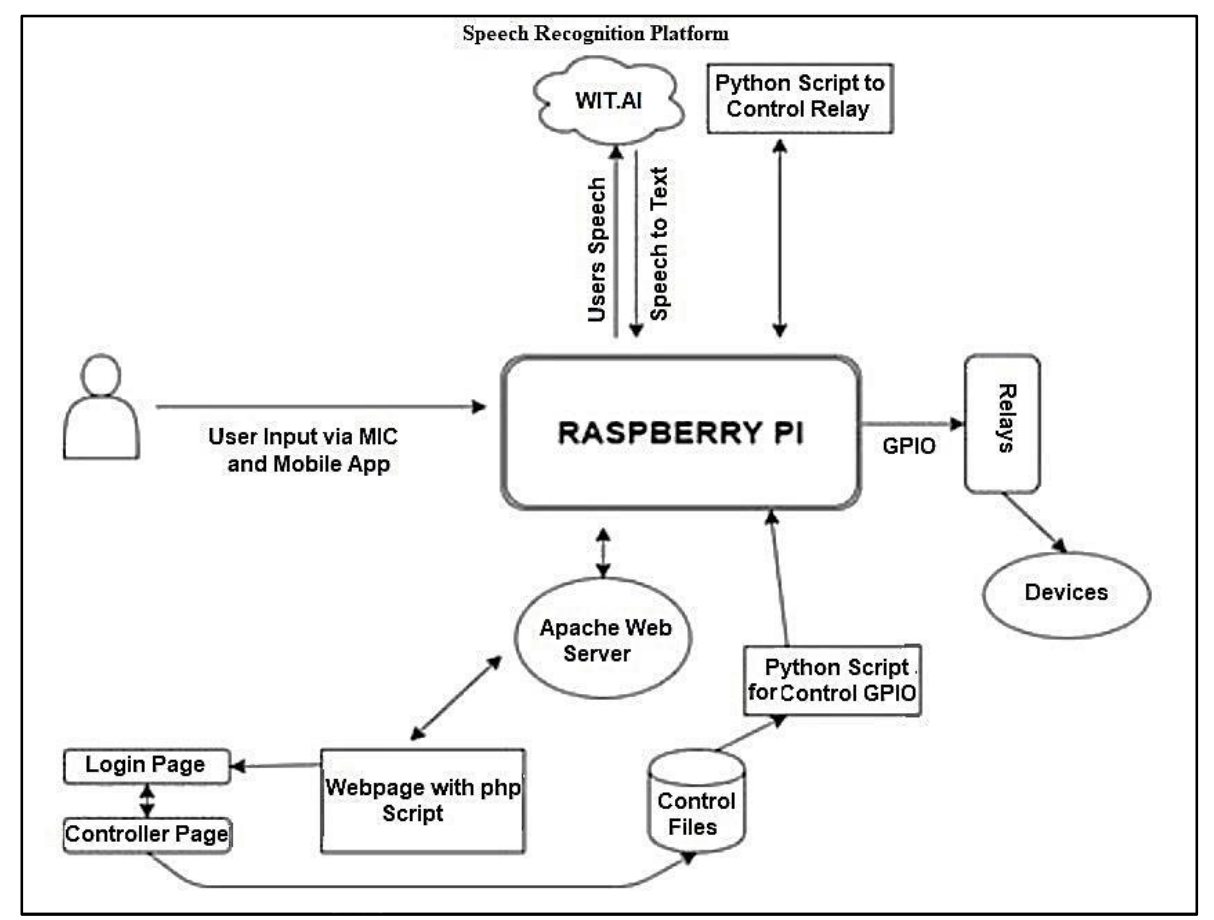

Fig.2. The architecture of proposed System

\section{HARDWARE - SOFTWARE ELEMENTS}

This paragraph includes how hardware and software components are designed, and the software systems needed to be built. 


\subsection{Hardware required parts:}

This type of systems needed microcontroller [6], which must be modern with other parts as follow:

- Raspberry PI

- The relay unit

- Wi-Fi dongle

- Energy sector

- USB sound card

- Internet connection

Raspberry PI is a BCM2835 system-on-chip (SoC)-based, credit card-sized device that contains an ARM11 processor and a strong GPU. Raspberry Pi is compatible with several Linux versions like Ubuntu, Fedora, and Arch Linux. This object is Raspberry Pi Model B, revision 2.0 involving the Maximum PCB CAD Catalog. The main features of this Raspberry PI are [7]:

- RAM $512 \mathrm{MB}$

- Ethernet port

- Two USB ports

- Two Options for Video output: HDMI or composite

- Audio-output jack $3.5 \mathrm{~mm}$

- 26-pin GPIO header of $0.1^{\prime \prime}$ male separated pins compliant of 2 women's headers that can be combined. Figure 3 shows the proposed model B, Ver. 2.0 of Raspberry PI.

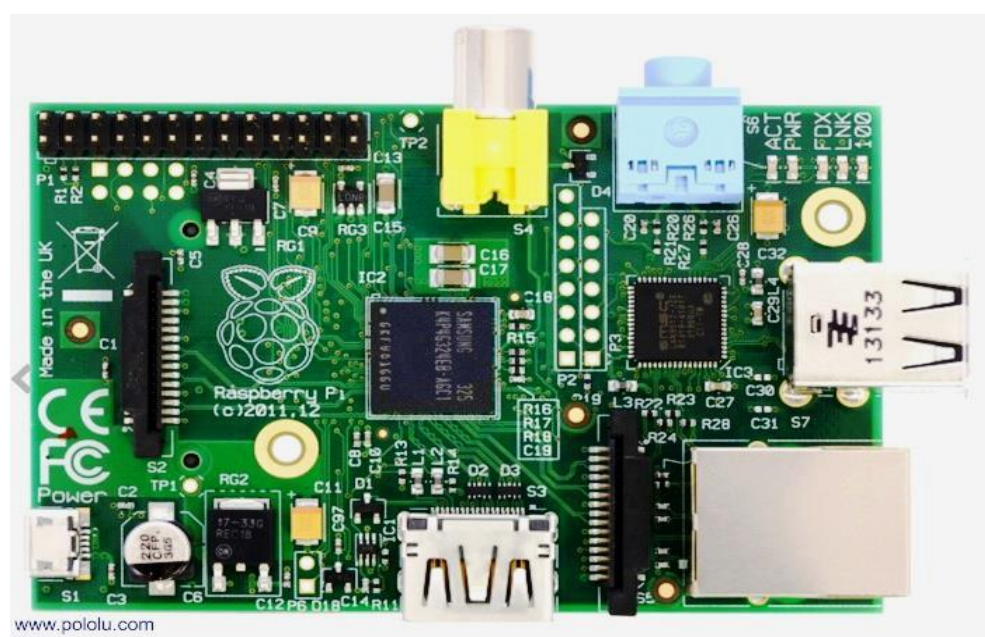

Fig.3. Raspberry PI Model B, Ver. 2.0 [7]

\subsection{Required Software}

- PHP

- Python

- MySQL

- HTML

- CSS 
- JavaScript

\subsection{Mobile Development Software Tools}

The software satisfies a hybrid application that can be run on multiplatform like Android/iPhone and other platform [8], so the tools can be used for this system as follows:

- Ionic Lab

- PhpStorm

- $\quad$ PhoneGap and Ionic Package [9]

- Android SDK for android

- $\quad$ iOS SDK for iPhone

\section{EXPERIMENTAL RESULTS}

The design of the suggested framework requires getting IP and running scripts that are done as follows:

\subsection{After installing, restart pi and get its IP address via command:}

1. "ifconfig": Test the inet key of wlan0, which would be the IP address.

2. Operate the "Main-Program" python script to launch GPIO delivery.

3. Run the python (speech recognition) script in a same certain place to react with the microphone / mobile (before running this script, make sure to update (speech recognition library) on pi using: "pip install speech recognition" on the terminal which will render:

A. The platform script utilizes wit.ai to execute speech appreciation using a speech recognition library via the cloud, as shown in Figure 2 previously.

B. Build API key based on wit.ai, and add it to the script file as shown in Figure 4.

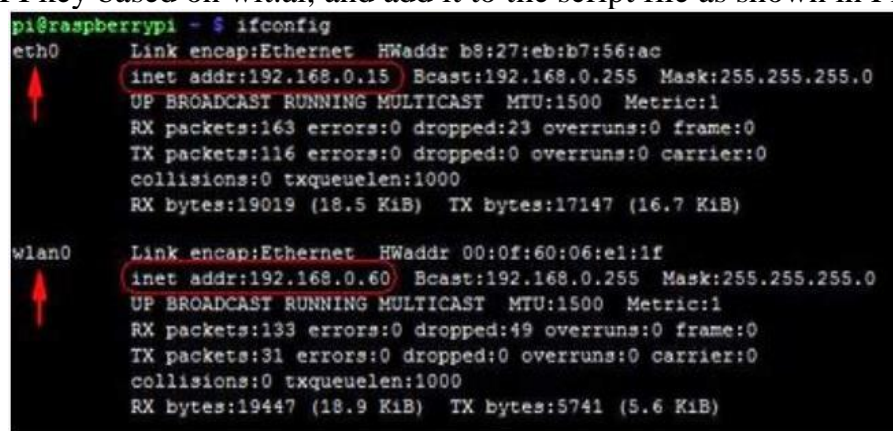

Fig.4. Shows the inet address in wlan0 (IP address)

\subsection{Derives Connection}

Figure 5 shows the connection of the relay module with the devices, the following steps explain that connection:

A. Connect the relay module with Raspberry pi to 5V and GND.

B. Plug the module signal pins with a head of GPIO 5, 7, 11 and 13 respectively. 
C. Press the wires from all the power strip switches and connect them to normally open stations from each relay.

D. Connect the USB with a power strip and connect Raspberry Pi using the wall adapter.

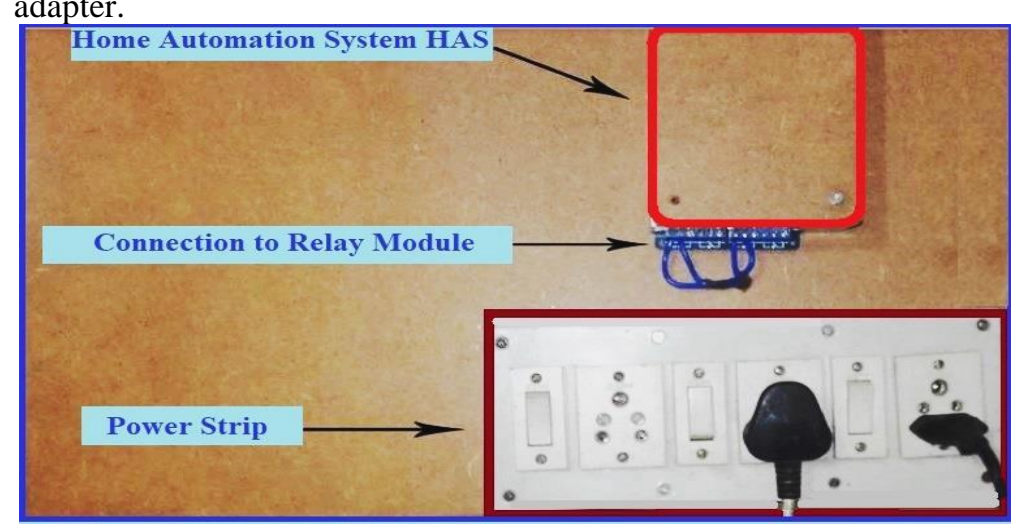

Fig.5. Shows relay module connection with proposed HAS

5.3. For controlling the devices using the proposed system via web Interface which are designed for this purpose, trace the following steps:

1. On a local machine / mobile device, go to the IP address on the same network that will lead to the home page as seen in Figure 6.

2. The user writes admin as user name and IOT as password.

3. Then the control site turns the devices in the house $\mathrm{ON}$ and OFF concerning device status.

4. When the user provides an audio command such as "TVon", the GPIO 5 activates the relay leading the TV to be turned ON, while "TVoff" command turns the TV OFF.

5. All other commands must be provided in the Python script to become other devices ready to use.

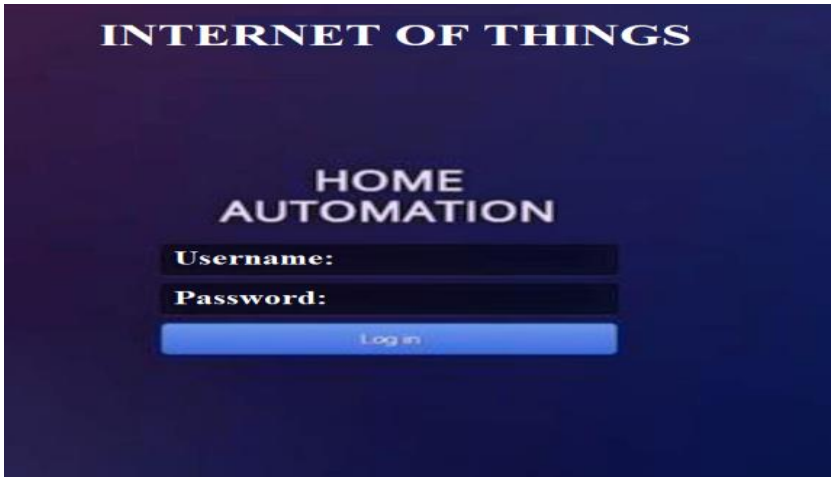

Fig.6. Shows homepage of proposed system

\subsection{Discussion Results:}

The implementation of the proposed HAS reveals the efficiency of this system for persons with disabilities compared to other related systems as shown in Table (2). 
Table 2. The correlation states between the suggested automatic method and the other methods

\begin{tabular}{|c|c|c|c|c|}
\hline Feature & $\begin{array}{l}\text { PROPOSED } \\
\text { SYSTEM }\end{array}$ & Ayad G. Ismaeel [3] & $\begin{array}{l}\text { Mohd H. Abd } \\
\text { Wahab[5] }\end{array}$ & $\begin{array}{c}\text { Shih-C. Chen, } \\
\text { Chung-M. Wu, \& et } \\
\text { al [4] }\end{array}$ \\
\hline $\begin{array}{l}\text { Which type of } \\
\text { people } \\
\text { disabilities } \\
\text { used }\end{array}$ & $\begin{array}{c}\text { Persons } \\
\text { with } \\
\text { Different } \\
\text { Types of } \\
\text { Disabilities. } \\
\text { effective }\end{array}$ & $\begin{array}{c}\text { For specific disabled } \\
\text { and non-disabled } \\
\text { persons }\end{array}$ & $\begin{array}{l}\text { Physical and } \\
\text { elderly }\end{array}$ & $\begin{array}{l}\text { only for people with } \\
\text { severe disabilities }\end{array}$ \\
\hline Cost & $\begin{array}{l}\text { cost } \\
\text { relatively to } \\
\text { Others } \\
\text { Yes }\end{array}$ & About $30 \$$ & Not Cheap & More cost \\
\hline $\begin{array}{l}\text { Remote } \\
\text { Control }\end{array}$ & $\begin{array}{l}\text { (anywhere, } \\
\text { i.e. } \\
\text { worldwide) }\end{array}$ & $\begin{array}{c}\text { Yes (anywhere, i.e. } \\
\text { worldwide) }\end{array}$ & Yes & Yes \\
\hline $\begin{array}{l}\text { Microcontroller } \\
\text { as computer }\end{array}$ & $\begin{array}{c}\text { Raspberry } \\
\text { Pi Model } \\
\text { B, revision } \\
2.0\end{array}$ & $\begin{array}{l}\text { Arduino Uno \& } \\
\text { ESP8266 }\end{array}$ & $\begin{array}{l}\text { Arduino Uno \& } \\
\text { Cytron BlueBee }\end{array}$ & Arduino Uno \\
\hline $\begin{array}{l}\text { IoT Home } \\
\text { Automated } \\
\text { Based on } \\
\text { Cloud }\end{array}$ & There is & There is & $\mathrm{x}$ & $\mathrm{x}$ \\
\hline $\begin{array}{l}\text { Mobile App. } \\
\text { addition to } \\
\text { MIC }\end{array}$ & Supported & $\begin{array}{l}\text { Supported by Mobile } \\
\text { different platform }\end{array}$ & Only Android & $\mathrm{x}$ \\
\hline $\begin{array}{c}\text { Data between } \\
\text { user via }\end{array}$ & & & & \\
\hline $\begin{array}{c}\text { MIC/mobile } \\
\text { and device } \\
\text { based Cloud }\end{array}$ & There is & There is & $\mathrm{x}$ & PC, Mobile etc. \\
\hline $\begin{array}{l}\text { The input by } \\
\text { speech feature }\end{array}$ & There is & There is & $\mathrm{x}$ & $\mathrm{x}$ \\
\hline
\end{tabular}

\section{CONCLUSIONS AND FUTURE WORKS}

The implementation of suggested HAS based on IOT via speech feature, which supports people with different types of disabilities shows the following conclusions:

1. Design the proposed AHS is effective-cost efficient.

2. The system supporting people with different types of disabilities using speech via MIC or Mobile App was satisfactory and to in configuring and use.

3. Secure and reliable.

4. This proposed architecture offers the strongest remote/local control approach that can be accessed everywhere via the cloud to electrical/electronic devices.

The future works can be summarized as follows: summary as follows: 
- Adding more features to the proposed HAS to help to hear as an important type of disability by using e.g. light sensors/LED monitors to give them flags when they require switching ON or OFF their devices.

- Adding a timer to the proposed HAS to provide other types of control that need a timer to turn $\mathrm{ON}$ or OFF.

\section{References}

[1] Shampa Sen, Leonid Datta and Sayk Mitra. (2019). "Machine Learning and IoT: A Biological Perspective": CRC Press (C) Taylor \& Francis Group, LLC, US Government, 2019.

[2] Global Initiative for Inclusive Information and Communications Technologies (July 2015), " Internet of Things: New Promises for Persons with Disabilities" (c) G3ict White Paper BusinessCase Series, 2015. https://g3ict.org/upload/publication/internet-of-things-new-promises-forpersons-with-disabilities/IoT_new-promises-for-PWD.pdf (17 -3- 2020)

[3] Ayad Ghany Ismaeel and Mohammed Qasim Kamal (April 2017), "Worldwide auto-mobi: Arduino IoT home automation system for IR devices", International Conference on Current Research in Computer Science and Information Technology (ICCIT), IEEE Xplor, Iraq, pp 5257.

[4] Shih-C. Chen, Chung-M. Wu, \& et al (2017), "Smart Home Control for the People with Severe Disabilities" International Conference on Applied System Innovation (ICASI), IEEE Xplore DOI: 10.1109/ICASI.2017.7988465, pp. 503-506.

[5] Mohd Helmy Abd Wahab (2016), "IoT-based home automation system for people with disabilities" 5th International Conference on Reliability, Infocom Technologies and Optimization (ICRITO),IEEE Xploer, DOI: 10.1109/ICRITO.2016.7784923, India.

[6] Ayad Ghany Ismaeel, Raghad Zuhair Yousif, Essa F. Abdallh (2013), "GUI Based Remote Control of (Gas Reduction System) using PIC Microcontroller”, IRACST - Engineering Science and Technology: An International Journal (ESTIJ), ISSN: 2250-3498, Vol.3, No.2, April 2013. pp 217-227. https://arxiv.org/ftp/arxiv/papers/1305/1305.0668.pdf

[7] Raspberry PI Model B, Ver. 2.0. URL: (date 20-03-2020, https://www.pololu.com/product/2750)

[8] R. G. Anmol Khandeparkar, B.Sindhya (May 2015), "An Introduction to Hybrid Platform Mobile Application Development," International Journal of Computer Applications, vol. 118, pp. 31-33.

[9] Chris Griffith, "Mobile App Development with Ionic 2 Cross-Platform Apps with Ionic, Angular, and Cordova”, Publisher: O'Reilly Media Release at April 201, Pages: 294. 